\title{
THE MECHANICS OF SHELL-CARRYING BY THE CLAUSILIID EUXINA CIRCUMDATA (PFEIFFER, 1848)
}

\author{
AYDIN ÖRSTAN \\ Section of Mollusks, Carnegie Museum of Natural History, Pittsburgh, Pennsylvania, 15213, U.S.A. \\ (e-mail: pulmonate@earthlink.net)
}

ABSTRACT: This study compared the growths of the foot and the shell of the clausiliid snail Euxina circumdata during its ontogeny. Also monitored was how the snails carried their shells in apparent conformity with the changes in the relative dimensions of their shells and feet. In juvenile snails foot lengths were comparable to shell lengths, but the feet stopped growing before the shells reached adult sizes. As a result, adults had feet much shorter than their shells. Juvenile snails could raise their shells, but the adults dragged them. A torque equation is presented to explain the relation between the shell and foot dimensions and the angle at which the shell is carried.

KEY WORDS: Clausiliidae, foot, ontogeny

\section{INTRODUCTION}

The gastropod foot is the organ of locomotion and attachment. The foot also carries and manoeuvres the external shell and the viscera within. The locomotion of gastropods has been the subject of many studies (JONES 1975, TRUEMAN 1983), but the mechanics of shell carrying has attracted much less attention. Shell carrying can be decoupled from locomotion, because even a stationary snail may raise and balance its shell.

The snails in the family Clausiliidae are intriguing subjects for the study of shell carrying, because while juvenile clausiliids carry their shells propped up on the backs of their feet, adult snails with shells that are much longer than they are wide can only drag their

\section{MATERIALS AND METHODS}

Live E. circumdata were from Burgaz Island in the Sea of Marmara off Istanbul, Turkey $\left(40.8788^{\circ} \mathrm{N}\right.$, $29.0655^{\circ} \mathrm{E}$ ). The snails were maintained in plastic boxes and fed various foods, including carrots, mushrooms, tree bark covered with cyanobacteria, toilet paper and powdered limestone. A batch of eggs laid by one of the adults provided the juveniles for this study. shells. Also, the feet of adult clausiliids are usually much shorter than their shells (Figs 1-6). These observations suggest that how a clausiliid carries its shell changes in correlation with the changes in the relative dimensions of the snail's foot and shell.

To support these casual observations with firmer data, I monitored the changes in the foot and the shell dimensions and the shell carrying angles of the clausiliid Euxina circumdata (Pfeiffer, 1848) during its ontogeny. I also present a simple physical model to explain the relation between foot and shell dimensions and the accompanying changes in shell carrying angles.

Shell length was measured from the apex to the bottom of the lip with calipers. The lengths of the extended feet and the shell carrying angles of snails were measured on photographs of snails using Image J (http://rsb.info.nih.gov/ij/). At least 12 individuals of $E$. circumdata (shell length $=2-12.4 \mathrm{~mm}$ ) were photographed, some on multiple occasions as they grew, either from the side or from below as they were crawl- 


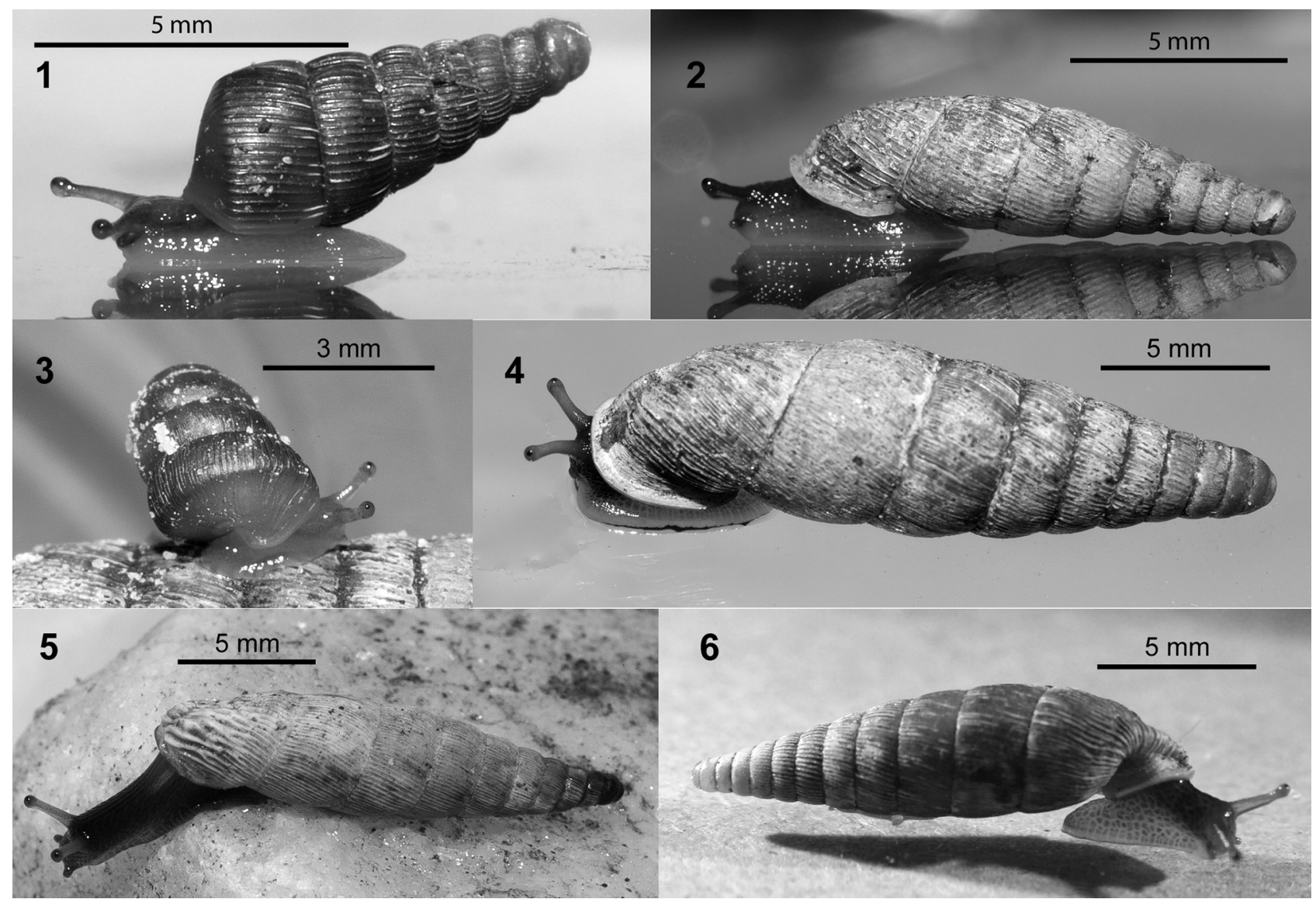

Figs 1-6. The position of the shell during crawling on horizontal surfaces in clausiliids: 1, 2 - juvenile and adult $E$. circumdata (Pfeiffer), 3, 4-juvenile and adult E. persica (Boettger), 5-adult Albinaria caerulea (Deshayes), 6 - adult Bulgarica denticulata (Olivier)

ing horizontally. The shell length of each snail was used as a scale to determine its foot length. I defined the shell carrying angle as the angle between the line from the apex of a shell to the base of the aperture and the horizontal line from the base of the aperture towards the tail of a snail (inset to Fig. 8). When the apex-to-aperture line was below the horizontal, its angle was taken to be negative. I measured the foot length and the shell carrying angle of each specimen on at least two photographs and report the values as mean \pm standard error.

To construct the shell profile of E. circumdata, I photographed the ventral sides of four adult shells (approximately spanning the range of the available adult shell lengths). Using ImageJ, for each shell I measured 19 diameters, perpendicular to a line from the apex to the bottom of the lip, starting at one twentieth (0.05) of shell length from the apex and continuing at increments of $(0.05 \times$ shell length $)$ until the nineteen twentieth $(0.95)$ of shell length was reached (I could measure only 17 diameters for one $E$. circumdata shell with a damaged aperture). I normalised each diameter by dividing it by the maximum diameter of each specimen and then plotted the values against the corresponding shell length increments.

\section{RESULTS}

Juvenile E. circumdata carried their shells raised on the back of their feet (Fig. 1) at angles varying from $12^{\circ}$ to $19^{\circ}$, but the angles decreased as the snails approached adulthood (Fig. 7). Two subadult snails with shells $9.6 \mathrm{~mm}$ and $10.7 \mathrm{~mm}$ long either dragged their shells or raised them up to angles of about $17^{\circ}$ and $7^{\circ}$, respectively. All adult E. circumdata dragged their shells with the antepenultimate whorl touching the surface (Fig. 2).

In the smallest specimens of E. circumdata (shell length $=2 \mathrm{~mm}$ ) the foot and the shell were almost the same length, but the subsequent growth of the foot was much slower than that of the shell. After the shell length reached about $6.5 \mathrm{~mm}$, the growth of the foot stopped or slowed down considerably (Fig. 8). As a result, the feet of adult snails were much shorter than their shells (Fig. 2). 


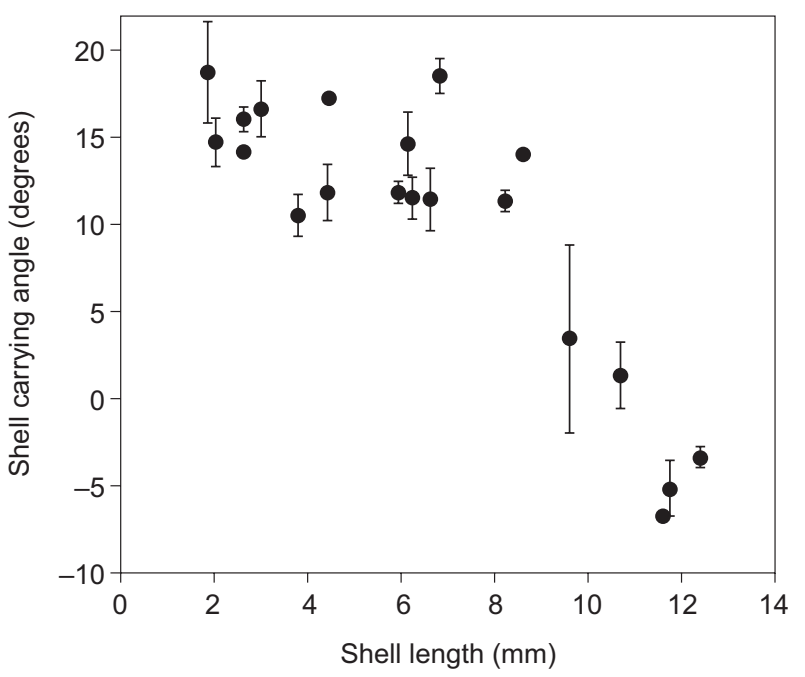

Fig. 7. Shell carrying angle versus shell length of $E$. circumdata. The values are mean \pm standard error (standard errors $\leq 0.5$ were omitted for clarity)

The shell diameter of E. circumdata increases during the first eight or nine whorls representing the juvenile stages, but begins to plateau when the shell length nears half of the adult shell length. A broad peak then forms before the shell diameter starts to decrease along the body (ultimate) whorl (Fig. 9).

\section{DISCUSSION}

The columellar muscle is responsible both for pulling the head-foot of a snail into its shell (FRETTER \& GRAHAM 1994) and for balancing the shell (CAIN 1977). To model the mechanistic relation between a snail's foot and shell, I have represented them as a pair of levers rotated by the columellar muscle around a pivot, p (Fig. 8, inset). Any adhesive force the sole may exert on the ground combined with the weight of the foot $\left(F_{f}\right)$ act on the foot at its center of gravity at a distance $\mathrm{f}$ from $\mathrm{p}$, while the combined weights of the shell and the viscera within act on the shell $\left(\mathrm{W}_{\mathrm{s}}\right)$ at its center of gravity at a distance $\mathrm{s}$ from $\mathrm{p}$. The shell carrying angle is $\rho$ (Fig. 8 , inset). The snail's foot will be horizontal at static equilibrium when the sum of the torques about $\mathrm{p}$ is zero (HALLIDAY et al. 2008). To keep the torque equation manageable, I assume that the sum of the weights of a snail's shell and foot $\left(\mathrm{F}_{\mathrm{f}}+\mathrm{W}_{\mathrm{s}}\right)$ as well as the opposing normal force act through the pivot and, therefore, do not enter into the torque equation. The torque equation can then be rearranged as follows:

$$
\mathrm{fF}_{\mathrm{f}}=\mathrm{sW}_{\mathrm{s}} \cos \alpha
$$

Three aspects of this equation are relevant to the data at hand. First, as $\mathrm{s}$ and $\mathrm{W}_{\mathrm{s}}$ increase during ontogeny, to maintain $\alpha$ constant the snail's foot must grow

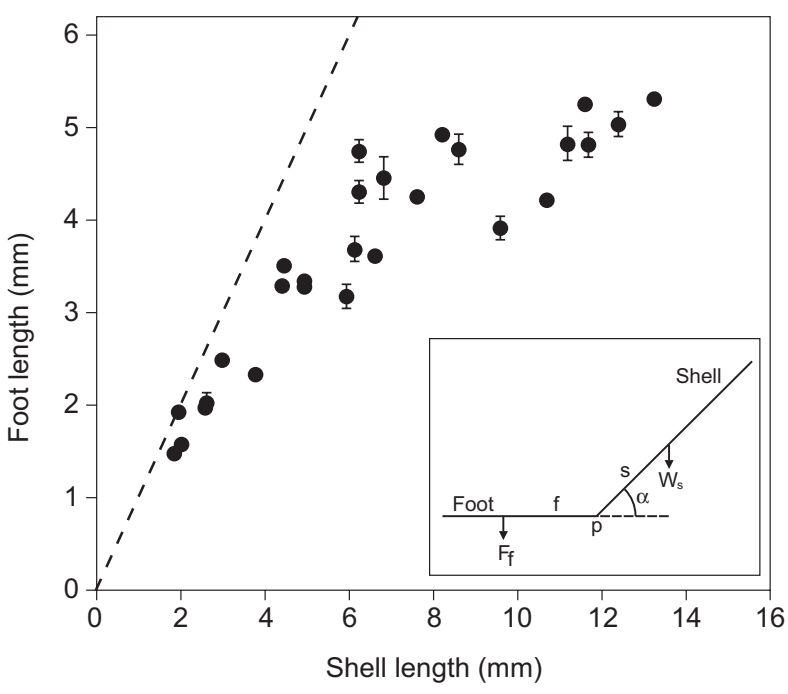

Fig. 8. Foot length versus shell length of E. circumdata. The values are mean \pm standard error (standard errors $\leq 0.1$ were omitted for clarity). The dotted line is for isometric (1:1) growth. Inset: A snail's foot and shell modelled as a pair of levers. See text for abbreviations

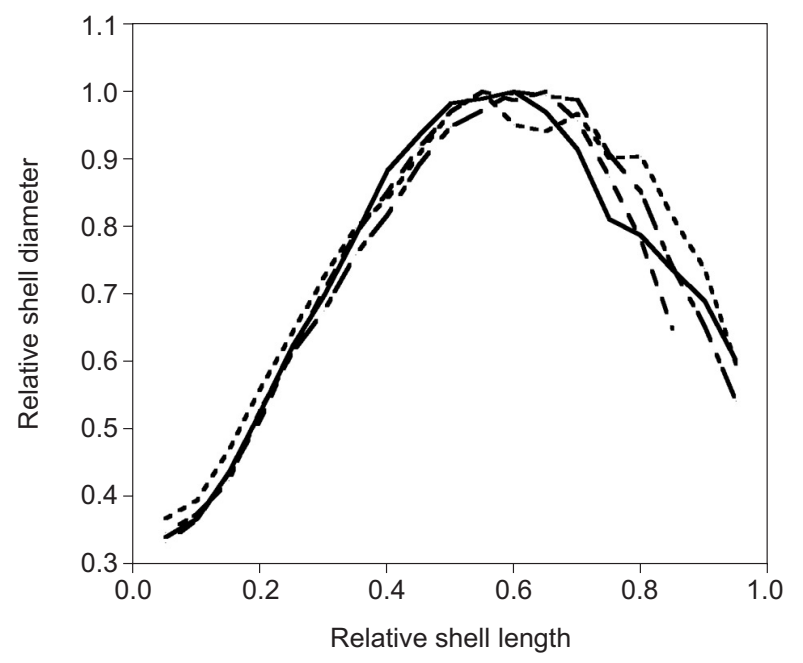

Fig. 9. Shell profiles for four adults of E. circumdata. The lines connect the relative whorl diameters measured at intervals of $1 / 20$ th of shell length. Individual data points were omitted for clarity

proportionately so that the term $\left(\mathrm{f}_{\mathrm{f}}\right)$ will balance the term $\left(\mathrm{s} \mathrm{W}_{\mathrm{s}}\right)$. This can be achieved by growing the foot longer, wider or heavier. Second, if the growth of the foot cannot keep up with that of the shell, to counteract the term $\left(\mathrm{s} \mathrm{W}_{\mathrm{s}}\right), \cos \alpha$ needs to get smaller $(\alpha$ needs to get larger). This means, perhaps counterintuitively, that when the shell length far exceeds the foot length, a snail needs to raise its shell higher to keep its foot horizontal. Recent analyses of shell geometries, without taking into account foot dimensions, also showed that the torque acting on a shell is minimised when its columella is perpendicular to the horizontal surface underneath the snail 
(OKAJIMA \& CHIBA 2011, 2013). However, rather than raise their shells to near perpendicular angles, which would make a tall shell difficult to balance (LINSLEY 1978, OKAJIMA \& CHIBA 2013) and manoeuvre, especially for litter-dwelling species, such as E. circumdata, adult clausiliids drop their shells and start dragging them. In addition to the data given here for E. circumdata, a similar change in the mode of shell carrying was also observed between the juveniles and the adults of E. persica (Figs 3-4). Shell dragging introduces friction, which may slow down locomotion. However, the clausiliids, being lichenivorous, herbivorous or detritivorous, may have little need for speed and thus friction may hardly be a trade-off.

Finally, equation (1) explains the observed variability of the shell carrying angle of juvenile $E$. circumdata (Fig. 7). If the angle changes from $\alpha_{1}$ to $\alpha_{2}$, while $f, s$ and $W_{s}$ stay the same (at any given stage during the growth of an individual), the equation may be rearranged as follows.

$$
\cos \alpha_{2} / \cos \alpha_{1}=\mathrm{F}_{\mathrm{f}, 2} / \mathrm{F}_{\mathrm{f}, 1}
$$

The ratio $\mathrm{F}_{\mathrm{f}, 2} / \mathrm{F}_{\mathrm{f}, 1}$ represents the relative burden on the foot resulting from changes in $\alpha$. This burden is imposed on the foot primarily by the columellar muscle. The rate of change of the slope of the cosine function is less between about $+20^{\circ}$ and $0^{\circ}$ than it is between about $+20^{\circ}$ and $+90^{\circ}$. Therefore, the changes in $\alpha$ when it is below $20^{\circ}$ impose less of a burden on a snail's foot than do the changes when $\alpha$ is above $20^{\circ}$. For example, if the shell is lowered from $20^{\circ}$ to $0^{\circ}$, $\mathrm{F}_{\mathrm{f}, 2} / \mathrm{F}_{\mathrm{f}, 1}$ would be 1.06 , but if it is lowered from $50^{\circ}$ to $30^{\circ}, \mathrm{F}_{\mathrm{f}, 2} / \mathrm{F}_{\mathrm{f}, 1}$ would be 1.35 . This may explain not only why juvenile $E$. circumdata keep their shells at angles below $20^{\circ}$, but also the observed variability of the angle itself (Fig. 7).

After a snail withdraws into its shell, its foot normally occupies the body whorl. Therefore, the vol- umes of the body whorl and the foot are expected to constrain each other mutually. It follows that the adult size of a snail's foot cannot change without concurrent changes in the size of the body whorl and shell shape. The foot of E. circumdata stops growing when the shell diameter, used here as a proxy for whorl volume, begins to plateau as the shell length reaches about half of the adult shell length (Fig. 9). Similar shell profiles would be obtained for all clausiliid species with tall adult shells (Figs 4-6). However, it is unlikely that the specific shape of the clausiliid shell, approximating a spindle, influences how the shell is carried. I note that shell-dragging is observed in almost all snail species with shells that are much taller than they are wide, including marine snails (LINSLEY 1978). For example, subulinids with tall shells that are not spindle-shaped, including adult Rumina, which have truncated shells, also drag their shells.

The volume of the body whorl of an adult clausiliid shell, being much smaller than the total shell volume, limits the size of the foot necessarily to a volume much smaller than the total shell volume. Moreover, an adult clausiliid needs to be able to withdraw its foot beyond the clausilium, located within the body whorl, into the penultimate whorl. This may put a further limit on the size of the foot relative to that of the shell volume. The relative sizes of the shell and the foot in turn dictate how a clausiliid will carry its shell. The equation (1) predicts that a hypothetical adult clausiliid with a long shell and a proportionately long foot would be able to raise its shell, but such a snail would not have room for its foot in its shell.

\section{ACKNOWLEDGEMENTS}

I thank TIM PEARCE for offering helpful comments on an earlier draft.

\section{REFERENCES}

CAIN A. J. 1977. Variation in the spire index of some coiled gastropod shells, and its evolutionary significance. Philos. Trans. Roy. Soc. B: Biol. Sci. 277: 377-428. http://dx.doi.org/ 10.1098/rstb.1977.0026

FRETTER V., GRAHAM A. 1994. British prosobranch molluscs. Their functional anatomy and ecology. Ray Society, London.

HALlidAY D., RESNICK R., WALKER J. 2008. Fundamentals of physics. Wiley, Hoboken.

JONES H. D. 1975. Locomotion. In: FretTer V., PEAKe J. F. (eds), Pulmonates, Vol. 1. Academic Press, London, pp. $1-31$.

LINSLEY R. M. 1978. Locomotion rates and shell form in the gastropoda. Malacologia 17: 193-206.
OKAJIMA R., CHIBA S. 2011. How does life adapt to a gravitational environment? The outline of the terrestrial gastropod shell. Am. Nat. 178: 801-809. http://dx.doi.org/ $10.1086 / 662674$

OKaJima R., CHIBA S. 2013. Adaptation from restricted geometries: the shell inclination of terrestrial gastropods. Evolution 67: 429-437. http://dx.doi.org/10.1111/ j.1558-5646.2012.01772.x

TRUEMAN E. R. 1983. Locomotion in molluscs. In: SAleuddin A. S. M., WilbuR K. M. (eds), The Mollusca, Vol. 4. Academic Press, London, pp. 155-198.

Received: March 15th, 2013 Revised: June 28th, 2013 Accepted: July 1st, 2013 